\title{
Adult Cystic Nephroma
}

National Cancer Institute

\section{Source}

National Cancer Institute. Adult Cystic Nephroma. NCI Thesaurus. Code C7504.

A localized, well-circumscribed multilocular tumor lined by hobnail epithelium. It was previously classified along with pediatric cystic nephroma, as a separate entity from mixed epithelial and stromal tumors. Now it is classified within the spectrum of the mixed epithelial and stromal tumor family. Most of these tumors are benign. (WHO 2016). 